\section{RMD Open}

Rheumatic \& Musculoskeletal Diseases

\title{
Predictors of renal damage in systemic lupus erythematous patients: data from a multiethnic, multinational Latin American lupus cohort (GLADEL)
}

Cristina Reátegui-Sokolova (D), 1,2 Manuel F Ugarte-Gil (D), ${ }^{1,3}$ Guillermina B Harvey, ${ }^{4}$ Daniel Wojdyla, ${ }^{5}$ Guillermo J Pons-Estel (1D, ${ }^{6}$ Rosana Quintana, ${ }^{6}$ Rosa M SerranoMorales, ${ }^{6}$ Mónica P Sacnun, ${ }^{7}$ Luis J Catoggio, ${ }^{8}$ Enrique R Soriano (D, ${ }^{8}$ Mercedes A García, ${ }^{9}$ Verónica Saurit, ${ }^{10}$ Alejandro Alvarellos, ${ }^{10}$ Francisco Caeiro, ${ }^{10}$ Guillermo A Berbotto, ${ }^{11}$ Emilia I Sato, ${ }^{12}$ Eduardo Ferreira Borba Neto, ${ }^{13}$ Eloisa Bonfa, ${ }^{13}$ Ana Carolina de Oliveira e Silva Montandon, ${ }^{14}$ Nilzio A Da Silva, ${ }^{14}$ Fernando Cavalcanti, ${ }^{15}$ Gloria Vásquez, ${ }^{16}$ Marlene Guibert-Toledano, ${ }^{17}$ Gil A ReyesLlerena, ${ }^{17}$ Loreto Massardo, ${ }^{18}$ Oscar J Neira, ${ }^{19}$ Mario H Cardiel, ${ }^{20}$ Leonor A BarileFabris, ${ }^{21}$ Mary-Carmen Amigo, ${ }^{22}$ Luis H Silveira, ${ }^{23}$ Margarita Portela-Hernández, ${ }^{24}$ Ignacio Garcia de la Torre, ${ }^{25}$ María Inés Segami, ${ }^{26}$ Rosa Chacón-Diaz, ${ }^{27}$ María H Esteva-Spinetti, ${ }^{28}$ Graciela S Alarcón, ${ }^{29,30}$ Bernardo A Pons-Estel ${ }^{6}$ and On behalf of GLADEL

To cite: Reátegui-Sokolova C, Ugarte-Gil MF, Harvey GB, et al. Predictors of renal damage in systemic lupus erythematous patients: data from a multiethnic, multinational Latin American lupus cohort (GLADEL). RMD Open 2020;6: e001299. doi:10.1136/ rmdopen-2020-001299

Received 1 May 2020 Revised 16 July 2020 Accepted 21 October 2020

Check for updates

\section{(C) Author(s) (or their} employer(s)) 2020. Re-use permitted under CC BY-NC. No commercial re-use. See rights and permissions. Published by BMJ.

For numbered affiliations see end of article.

\section{Correspondence to} Cristina Reategui-Sokolova; cristina.reateguis@gmail.com

\section{ABSTRACT}

Aim A decrease in proteinuria has been considered protective from renal damage in lupus nephritis $(\mathrm{LN})$, but a cut-off point has yet to be established. The aim of this study was to identify the predictors of renal damage in patients with $L N$ and to determine the best cut-off point for a decrease in proteinuria. Methods We included patients with LN defined clinically or histologically. Possible predictors of renal damage at the time of LN diagnosis were examined: proteinuria, low complement, anti-double-stranded DNA antibodies, red cell casts, creatinine level, hypertension, renal activity (assessed by the Systemic Lupus Erythematosus Disease Activity Index (SLEDAI)), prednisone dose, immunosuppressive drugs and antimalarial use. Sociodemographic variables were included at baseline. Proteinuria was assessed at baseline and at 12 months, to determine if early response (proteinuria $<0.8 \mathrm{~g} /$ day within 12 months since LN diagnosis) is protective of renal damage occurrence. Renal damage was defined as an increase of one or more points in the renal domain of The Systemic Lupus International Collaborating Clinics (SLICC)/American College of Rheumatology (ACR) Damage Index (SDI). Cox regression models using a backward selection method were performed.

Results Five hundred and two patients with systemic lupus erythematosus patients were included; 120 patients $(23.9 \%)$ accrued renal damage during their follow-up. Early response to treatment $(\mathrm{HR}=0.58)$, antimalarial use $(\mathrm{HR}=0.54)$ and a high SES $(\mathrm{HR}=0.25)$ were protective of renal damage occurrence, whereas male gender $(H R=1.83)$, hypertension $(H R=1.86)$ and the renal component of the SLEDAI ( $H R=2.02)$ were risk factors for its occurrence. Conclusions Early response, antimalarial use and high SES were protective of renal damage, while male gender, hypertension and higher renal activity were risk factors for its occurrence in patients with $\mathrm{LN}$.

\section{Key messages}

What is already known about this subject?

- Most of the response criteria for lupus nephritis include proteinuria $<0.5 \mathrm{~g} /$ day at 12 months.

- However, proteinuria $<0.8 \mathrm{~g} /$ day at 12 months has proven to be a good predictor of long-term renal damage.

What does this study add?

- The proteinuria cut-off point of $<0.8 \mathrm{~g} /$ day at 12 months was protective of the occurrence of early renal damage.

- Antimalarial use and high SES were also protective of renal damage, while male gender, hypertension and higher renal activity were risk factors for its occurrence.

How might this impact on clinical practice?

- The proteinuria cut-off point at 12 months needs to be re-evaluated.

\section{INTRODUCTION}

Systemic lupus erythematosus (SLE) is a multisystemic autoimmune disease of unknown aetiology. Lupus nephritis (LN) is one of its most common and serious manifestations. A recent, large multiethnic, multinational, inception cohort of 1827 patients 
reported that LN occurred in $700(38.3 \%)$ of their patients with SLE and was more frequent in those of African, Asian or Hispanic ancestry. Despite standard of care, the estimated 10-year incidence of end-stage renal disease (ESRD) in these patients with LN was $4.3 \% .^{1}$ Additionally, LN significantly reduces the survival of patients with SLE, in particular in the proliferative types. $^{23}$

Treatment of LN should aim at inducing remission of kidney inflammation and maintaining remission of kidney inflammation so as to preserve renal function and improve survival. ${ }^{4}$ In fact, the induction of clinical remission in $\mathrm{LN}$ is predictive of long-term patient prognosis as well as of renal survival. ${ }^{5}$ There is no universal agreement on the definition of nephritis remission or low disease activity state, as well as the time points for changing therapies in these patients. ${ }^{4}$ It has been identified that even a partial remission has significantly better outcomes in those patients compared with those who did not achieve it. ${ }^{6}$

Although there are markers of $\mathrm{LN}$ such as proteinuria and haematuria, these findings are not sufficient to predict the extent and severity of kidney damage. This reinforces the need to identify predictors of renal damage accrual in patients with SLE and act upon them.

Previous studies have shown that the prognosis of LN depends on several factors including sociodemographic, clinical, serological and genetic features. ${ }^{7}$ It has also been demonstrated that higher uric acid levels contribute to the development of new renal damage in Peruvian patients with SLE. ${ }^{8}$ In addition, renal markers such as low creatinine clearance, proteinuria, hypertension and nephrotic syndrome are associated with poor prognosis among patients with $\mathrm{LN}{ }^{9}$

In a Caucasian population, proteinuria $<0.8 \mathrm{~g} / 24$ hours at 12 months has proven to be a predictor of good outcome in patients of the Euro-Lupus Nephritis Trial; the outcome was defined as a serum creatinine $\leq 1 \mathrm{mg} / \mathrm{dl} 7$ years after entry into the trial (sensitivity $=81 \%$ and specificity $=78 \%) .{ }^{10}$ In the MAINTAIN Nephritis Trial, proteinuria $<0.7 \mathrm{~g} /$ day was the best predictor of longterm renal outcome (sensitivity $=71 \%$ and specificity $=75 \%) .{ }^{11}$ In a Brazilian lupus population with severe nephritis from a tertiary centre (baseline mean creatinine of $1.73 \pm 1.34 \mathrm{mg} / \mathrm{dL}$ ), in which only $40 \%$ of the patients were non-Caucasian, demonstrated that proteinuria $<0.8 \mathrm{~g} / 24$ hours at 12 months of follow-up was the best predictor of long-term renal outcome. ${ }^{12}$ These three studies, however, evaluated only long-term renal damage, and therefore, they excluded patients with early development of ESRD, that is, within the first year after the nephritis episode.

There is limited information about predictors of kidney damage particularly in multiethnic lupus patients. Due to this, the objective of this study was to identify factors predictive of short-term renal damage in our Latin American population, a large, mixed race cohort with a standard follow-up.

\section{METHODS}

As previously described, GLADEL (Grupo LatinoAmericano De Estudio del Lupus) is a multiethnic, multinational, multicenter cohort, including 34 centres from nine Latin American countries participated by randomly incorporating patients with SLE within 2 years of diagnosis. ${ }^{13}$ Recruitment started in 1997 and finished in 2004. Patients were included in the cohort based on the physician's diagnosis; however, the large majority fulfilled four or more of the American College of Rheumatology (ACR) classification criteria for SLE. ${ }^{14}$

Data included socioeconomic-demographic and clinical characteristics, treatment features and laboratory tests. The general characteristics and composition of the entire GLADEL cohort have been described in detail elsewhere. $^{13}$

For this study, we included patients with LN defined clinically (proteinuria greater than $0.5 \mathrm{~g}$ /day on two or more occasions or the presence of red cell casts) or histologically (renal biopsy compatible with LN histopathology classes II, III, IV, V according to the WHO).${ }^{15}$ For these analyses, the follow-up started at the time LN was defined. Patients with ESRD (regardless of dialysis or transplantation) were excluded.

The following variables were considered as possible predictors of renal damage: proteinuria, low complement, anti-double-stranded DNA, red cell casts, creatinine level at the time LN was defined, hypertension, the renal component of the Systemic Lupus Erythematosus Disease Activity Index (SLEDAI), prednisone dose, use of immunosuppressive drugs and antimalarials. The following baseline variables were also included: gender, age at nephritis diagnosis, residence: rural or urban, ethnic group and socioeconomic status (SES).

Proteinuria was assessed at LN diagnosis and after 12 months, to determine if early response defined as proteinuria $<0.8 \mathrm{~g}$ /day within 12 months from the diagnosis of $\mathrm{LN}$ is protective of renal damage occurrence in patients with SLE. Previous reports studying long-term prognosis included patients with at least 7 years of followup; we defined short-term as a follow-up of less than 7 years. Renal damage was defined as an increase of at least one point in the renal domain of the SLICC/ACR damage index.

\section{STATISTICAL ANALYSES}

Categorical variables were summarised as frequencies and percentages, whereas continuous variables were presented as medians and their interquartile range (IQRs).

In order to evaluate the predictors of renal damage, univariable and multivariable Cox regression models were performed using a backward selection method with an alpha level to stay in the model set at 0.05 . We performed a model using the definition for early response as proteinuria $<0.8 \mathrm{~g} /$ day. We also made a receiver operating characteristic (ROC) curve to determine the best cut-off point for proteinuria. 
Three additional models were also carried out; one in which the renal component of the SLEDAI was omitted, a second one in which the components of renal damage were examined separately, and a third one in which only patients with biopsy-proven LN were included. Finally, a comparison between patients with proliferative and non-proliferative nephritis was also carried out.

Statistical analyses were performed using SAS software, version 9.1.3 (SAS Institute, Cary, NC, USA).

\section{RESULTS}

A total of 502 patients who fulfilled the inclusion criteria were included. Demographic and disease-related features are shown in table 1 . Most of the patients were females $(451 ; 89.8 \%)$, with a median age at SLE diagnosis of 26.0 IQR (19.0-35.0) years and median age at nephritis diagnosis of 27.0 (20.3-36.2) with a median follow-up after nephritis diagnosis of $3.6(1.6-5.2)$ years. Two hundred and one $(40.2 \%)$ were Caucasian, 224 (44.8\%) were Mestizo, 58 (11.6\%) were African-Latin American. At baseline, the median serum creatinine was $1.0 \mathrm{mg} / \mathrm{dl}$ IQR (0.8-1.2).

One hundred and twenty $(23.9 \%)$ patients achieved early response defined as proteinuria $<0.8 \mathrm{~g} /$ day.

One hundred and sixty-one patients $(32.1 \%)$ accrued renal damage during their follow-up (figure 1).

Univariable and multivariable models are depicted in table 2. Early response to treatment defined as proteinuria $<0.8 \mathrm{~g}$ /day within 12 months from the diagnosis of $\mathrm{LN}(\mathrm{HR}=0.58)$ and antimalarial use $(\mathrm{HR}=0.54)$ and a high SES $(\mathrm{HR}=0.25)$ were protective of the occurrence of renal damage, whereas male gender $(\mathrm{HR}=1.83)$, hypertension $(\mathrm{HR}=1.86)$ and the renal component of the SLEDAI $(H R=2.02)$ were risk factors for renal damage occurrence.

In the ROC curve, we found that the cut-off point of $0.8 \mathrm{~g} /$ day had good sensitivity and specificity, with area under curve of 0.57 , better than $0.5 \mathrm{~g} /$ day and $0.7 \mathrm{~g} /$ day with 0.53 and 0.56 , respectively.

In the alternative analysis in which the renal component of the SLEDAI was omitted, the results were consistent with those of the main analysis. Early response defined as proteinuria $<0.8 \mathrm{~g}$ /day within 12 months from the diagnosis of $\mathrm{LN}(\mathrm{HR}=0.57)$ and antimalarial use $(\mathrm{HR}=0.55)$ where protective of the occurrence of renal damage, whereas male gender $(\mathrm{HR}=1.74)$ and hypertension $(\mathrm{HR}=2.20)$ were risk factors for renal damage occurrence.

The components of renal damage: glomerular filtration rate $(\mathrm{GFR})<50 \%$, proteinuria $>3.5 \mathrm{~g} /$ day and ESRD have been examined as three distinct endpoints.

Eighty-nine patients $(89 / 502)$ reached GFR $<50 \%$. In a multivariable analysis, antimalarial use (OR 0.51, $\mathrm{p}=0.024$ ) and azathioprine (OR $0.08, \mathrm{p}=0.026$ ) use were protective, while hypertension $(\mathrm{OR} 3.55, \mathrm{p}<0.001)$ and cyclophosphamide use (OR 1.73, $\mathrm{p}=0.0405)$ were predictors of damage.

Twenty-four patients $(24 / 502)$ reached ESRD, but we were not able to identify any predictor in the analyses performed (data nor shown).

Ninety-five patients $(95 / 502)$ reached proteinuria $\geq 3.5 \mathrm{~g} /$ day for at least 6 months. In the multivariable

Table 1 Baseline features of patients with SLE with lupus nephritis defined clinically or histologically $(\mathrm{N}=502)$ and defined histologically ( $N=241)$ from the GLADEL cohort

\begin{tabular}{|c|c|c|}
\hline Variable & $\mathrm{N}=502$ & $\mathrm{~N}=\mathbf{2 4 1}$ \\
\hline Female gender, $\mathrm{n}(\%)$ & $451(89.8)$ & $211(87.6)$ \\
\hline Age at diagnosis, years, median (IQR) & $26.0(19.0-35.0)$ & $26.0(20.0-34.0)$ \\
\hline Age at nephritis diagnosis, years, median (IQR) & $27.0(20.3-36.2)$ & $26.8(20.3-34.7)$ \\
\hline Follow-up after nephritis diagnosis, years, median (IQR) & $3.6(1.6-5.2)$ & $2.9(0.9-4.9)$ \\
\hline Creatinine at baseline, $\mathrm{mg} / \mathrm{dl}$, median (IQR) & $1.0(0.8-1.2)$ & $1.0(0.8-1.4)$ \\
\hline Proteinuria at baseline, mg/day, median (IQR) & 1154 (500.0-2690.0) & $1600(700-3210)$ \\
\hline SDI at baseline, median (IQR) & $1.0(0.0-2.0)$ & $1(0-2)$ \\
\hline \multicolumn{3}{|l|}{ Ethnic group } \\
\hline Caucasian, $\mathrm{n}(\%)$ & $201 / 500(40.2)$ & $88(36.7)$ \\
\hline Mestizo, n (\%) & $224 / 500(44.8)$ & $117(48.7)$ \\
\hline Afro Latin-American, $\mathrm{n}(\%)$ & $58 / 500(11.6)$ & $25(10.4)$ \\
\hline Other, $\mathrm{n}(\%)$ & $17 / 500(3.4)$ & $10(4.2)$ \\
\hline \multicolumn{3}{|l|}{ Socioeconomic status } \\
\hline High, n (\%) & $31 / 499(6.2)$ & $13(5.4)$ \\
\hline Medium, n (\%) & $150 / 499(30.1)$ & $83(34.4)$ \\
\hline Low, n (\%) & $318 / 499$ (63.7) & $145(60.2)$ \\
\hline \multicolumn{3}{|l|}{ Residency } \\
\hline Urban, n (\%) & 456/500 (91.2) & $221(92.1)$ \\
\hline Rural, n (\%) & $44 / 500(8.8)$ & $19(7.9)$ \\
\hline
\end{tabular}

IQR, Interquartile range; SDI, Systemic Lupus International Collaborating Clinics/American College of Rheumatology Damage Index. 


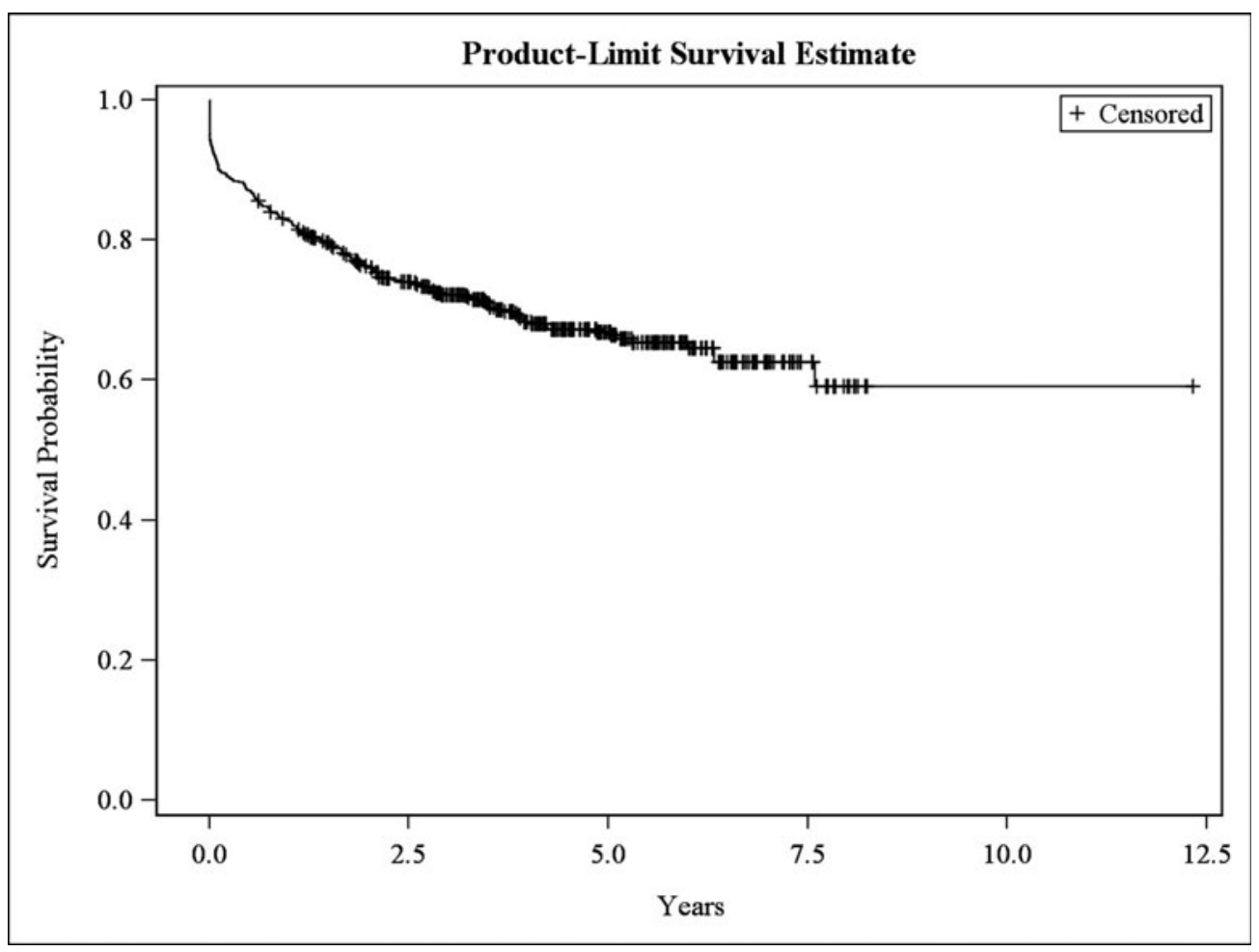

Figure 1 Kaplan-Meier curve: Renal damage-free survival curve. Patients with LN (clinically or biopsy-proven). $\mathrm{n}=502$.

Table 2 Predictors of renal damage in patients with lupus nephritis*

\begin{tabular}{|c|c|c|c|c|}
\hline & \multirow{2}{*}{$\frac{\text { Univariable }}{\text { HR }(95 \% \mathrm{Cl})}$} & \multirow[b]{2}{*}{$p$-value } & \multicolumn{2}{|l|}{ Multivariable } \\
\hline & & & HR $(95 \% \mathrm{Cl})$ & p-value \\
\hline Age at nephritis diagnosis & $0.99(0.97-1.00)$ & 0.049 & & \\
\hline Gender (male) & $1.60(1.04-2.48)$ & 0.033 & $1.83(1.17-2.86)$ & 0.008 \\
\hline Residence (rural) & $0.87(0.49-1.53)$ & 0.620 & & \\
\hline \multicolumn{5}{|l|}{ Ethnicity } \\
\hline Caucasian & Ref. & & & \\
\hline Mestizo & $1.51(1.07-2.13)$ & 0.191 & & \\
\hline African Latin-American & $1.41(0.84-2.35)$ & 0.195 & & \\
\hline Others & $1.04(0.38-2.89)$ & 0.933 & & \\
\hline \multicolumn{5}{|l|}{ SES } \\
\hline High & $0.27(0.10-0.74)$ & 0.011 & $0.25(0.09-0.69)$ & 0.007 \\
\hline Medium & $0.62(0.43-0.89)$ & 0.001 & $0.70(0.49-1.01)$ & 0.058 \\
\hline Low & Ref. & & Ref. & \\
\hline Early treatment response & $0.49(0.32-0.76)$ & 0.002 & $0.57(0.37-0.90)$ & 0.014 \\
\hline Proteinuria & $1.39(0.72-2.59)$ & 0.338 & & \\
\hline Low complement & $1.42(1.03-1.96)$ & 0.032 & & \\
\hline Anti-dsDNA & $1.28(0.94-1.75)$ & 0.118 & & \\
\hline Red cell casts & $2.10(1.54-2.87)$ & $<0.001$ & & \\
\hline Creatinine level & $1.18(1.09-1.26)$ & $<0.001$ & & \\
\hline Hypertension & $2.37(1.70-3.30)$ & $<0.001$ & $1.86(1.31-2.64)$ & $<0.001$ \\
\hline Renal component of SLEDAI & $2.26(1.62-3.16)$ & $<0.001$ & $2.02(1.43-2.84)$ & $<0.001$ \\
\hline Prednisone dose & $1.01(1.00-1.01)$ & 0.008 & & \\
\hline Immunosuppressive drugs use & $1.50(1.10-2.05)$ & 0.011 & & \\
\hline Antimalarial use & $0.454(0.37-0.79)$ & $<0.001$ & $0.54(0.37-0.79)$ & 0.002 \\
\hline
\end{tabular}

${ }^{*}$ Clinically or histologically.

Anti-dsDNA, Anti-double-stranded DNA; SES, Socioeconomic status; SLEDAI, Systemic Lupus Erythematosus Disease Activity Index. 
analysis, early response defined as proteinuria $<0.8 \mathrm{~g} /$ day was protective of nephrotic damage (OR 0.31, $\mathrm{p}<0.001$ ), whereas the presence of red cellular cast (OR 3.34, $\mathrm{p}<0.001)$ and male gender (OR 3.80, $\mathrm{p}<0.001)$ were associated with damage manifested as proteinuria $\geq 3.5 \mathrm{~g}$ /day.

Additional analyses were performed in those patients with biopsy-proven LN ( $\mathrm{n}=241)$ and in those with proliferative nephritis $(\mathrm{n}=162)$; as per the renal biopsy data, 58 patients were classified as (24.1\%) Class II, $24(9.9 \%)$ as Class III, $138(57.3 \%)$ as Class IV and $21(8.7 \%)$ as Class V LN. Of them, 113 (46.9\%) accrued renal damage during the follow-up (figure 2). We observed differences in terms of creatinine levels $(\mathrm{p}=0.009)$ between both groups, and difference in terms of proteinuria values being higher in those undergoing a renal biopsy $(\mathrm{p}=<0.001)$. High $\quad(H R=0.24)$ SES was protective from damage, whereas hypertension $(\mathrm{HR}=1.75)$ was predictive of damage in the multivariable analyses, as depicted in table 3 .

We compared proliferative (Class III and IV) vs nonproliferative nephritis (Class II and V). We found that non-proliferative nephritis accrued less damage (HR $0.75)$, however this finding was not statistically significant $(\mathrm{p}=0.178)$

\section{DISCUSSION}

Organ damage accrual is a predictor of further damage, morbidity and early mortality. ${ }^{16}$ Treat-to-target approach aims to improve management of SLE through target- based goals ${ }^{17}$; however, the treatment goal in LN has not been clearly defined. This study, performed in a Latin American population, demonstrated that early response defined as proteinuria $<0.8 \mathrm{~g}$ /day within 12 months from the diagnosis of $\mathrm{LN}$, antimalarial use and a higher SES are protective of renal damage occurrence. On the other hand, male gender, hypertension and renal activity were predictive of renal damage.

Regarding sociodemographic factors, male gender was a risk factor, and high SES was protective of renal damage occurrence in patients with SLE. Similarly, Cheng et al found that the phenotypic pattern and disease activity varied between Chinese patients with SLE by regional economic factors as educational level, availability of medical personnel and area of residency. ${ }^{18}$ In the Mestizo population, it has been demonstrated that rural residency is associated with high levels of disease activity and renal disease occurrence. ${ }^{19}$ We therefore do not have a good explanation for the fact that urban residence was predictive of renal damage, although this was only evident in the subgroup of patients with biopsy-proven LN.

We hypothesise that rural patients who require a renal biopsy need to be referred to an urban medical facility for the procedure; the ability to do so may reflect a higher SES in these patients than in those who ended up not having a biopsy.

To the best of our knowledge, there are no reports about SES and its relationship with renal damage in patients with SLE. 
Table 3 Predictors of renal damage. Patients with biopsy-proven lupus nephritis $(n=241)$

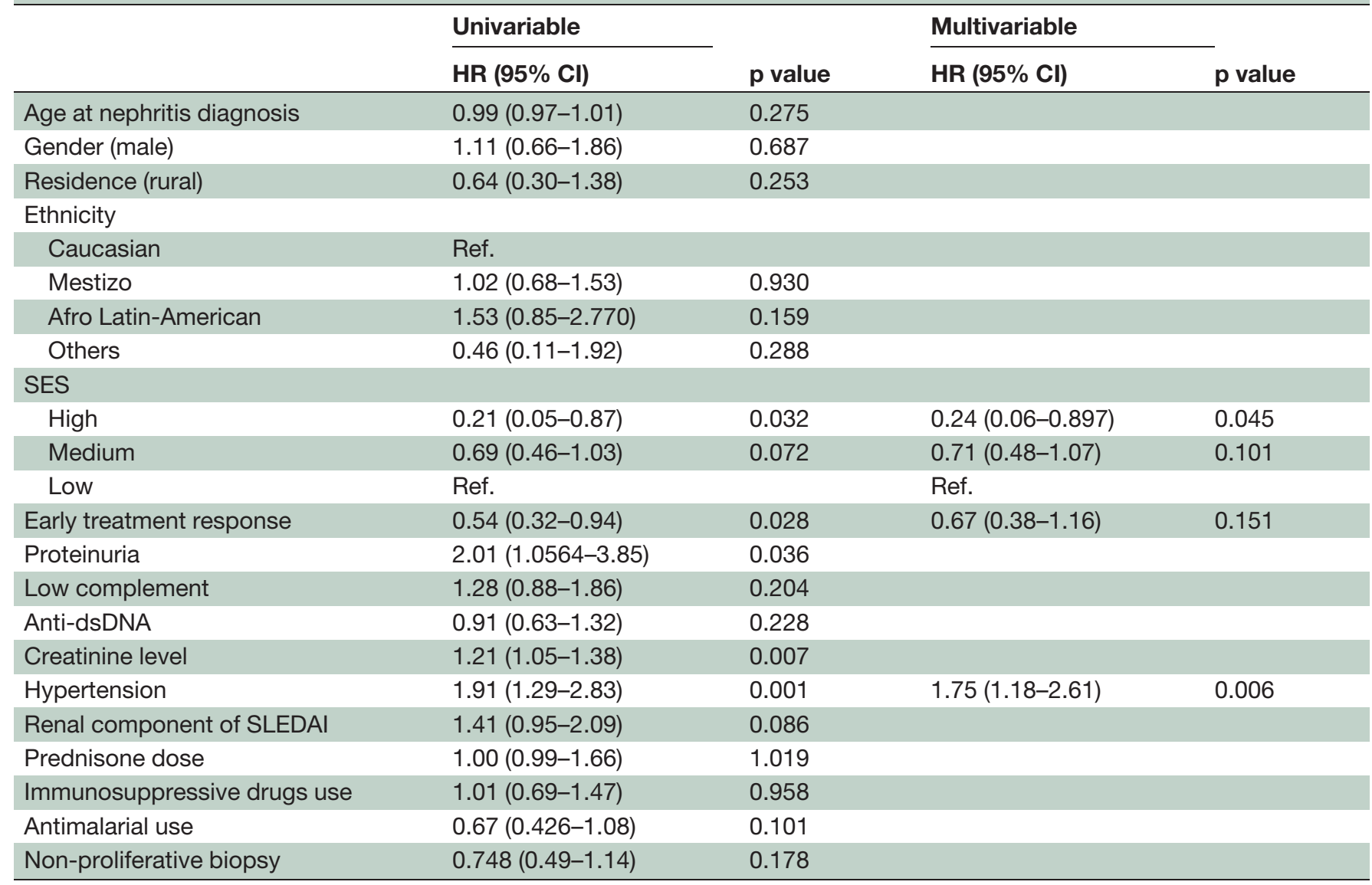

Anti-dsDNA, anti-double-stranded DNA; SES, Socioeconomic status; SLEDAI, Systemic Lupus Erythematosus Disease Activity Index.

A high score in the renal domain of the SLEDAI was predictive of damage; similar results were reported by Kandane et al; patients with active LN were more likely to accrue any organ damage compared with those without active LN $[\mathrm{HR}=1.5295 \%$ CI: $(1.16-1.97), \mathrm{p}=0.02] .^{20}$

The impact of proteinuria on renal damage was previously described in a Japanese population, in which achieving complete renal response (CR) was based on the Joint European League Against Rheumatism and European Renal Association-European Dialysis and Transplant Association (EULAR/ERA-EDTA) recommendations for LN, which were: a urine protein-tocreatinine ratio $50 \mathrm{mg} / \mathrm{mmol}$ and normal or nearnormal renal function; at 3 or 6 months was associated with maintaining $C R$ at 3 years $(p=0.029$ and $p=0.009$, respectively). ${ }^{21}$

Likewise, the impact of proteinuria at 12 months on renal damage is consistent with the long-term data from the Euro-Lupus Nephritis Trial, which included only Caucasian patients; the absolute level of proteinuria of $<0.8 \mathrm{~g} /$ day at 12 months was the best individual predictor of good long-term renal outcome at 7 years in these patients. ${ }^{10}$ Likewise, in another Caucasian cohort, a very similar proteinuria cut-off $(<0.7 \mathrm{~g} /$ day at 12 months $)$ to predict good long-term outcome ${ }^{11}$ was found. Importantly, in both studies, the addition of creatinine to the analyses did not improve the performance of proteinuria alone. And, in a population of mixed ethnic background, Ugolini et al reported in a real-life clinical setting, that proteinuria $<0.8 \mathrm{~g} / 24$ hours at 12 months was the best single predictor of being free from dialysis at 7 years, in patients with severe biopsy-proven LN. ${ }^{12}$

These studies, taking together, support the notion that a cut-off point different from proteinuria $\leq 0.5 \mathrm{~g} /$ day is needed; based on our current study and those of others, we suggest that the cut-off point of $0.8 \mathrm{~g} /$ day 12 months after LN onset could be a useful target. In fact, the 2019 update of the EULAR recommendations include proteinuria $\leq 0.8 \mathrm{~g} /$ day as a predictor of a favourable long-term outcome. ${ }^{22}$ In the analysis in which the individual components of the renal damage rather than overall renal damage were considered as the outcome, we found that the use of azathioprine was protective, whereas the use of cyclophosphamide was a predictor of a decrease in GFR $<50 \%$; we think that this is because cyclophosphamide could be used to treat patients with more severe manifestations of nephritis. We did not find the urine red blood cell count as a predictor in our analysis; we did so based on previous results in which the addition of urine red blood cells $\leq 5 / \mathrm{hpf}$ to proteinuria at 12 months decreased the sensitivity to predict good long-term renal disease. ${ }^{1011}$ 
Importantly, the present study confirms that antimalarial use protects from the development of renal damage. Previously, Pons-Estel et al have shown evidence that antimalarials are negatively associated with the occurrence of SLE renal disease ${ }^{2324}$; taken together, our data reinforces the importance of the use of antimalarials in the treatment of SLE.

Additionally, we found hypertension to be a predictor of damage; similar information has been reported in Chinese patients with LN in which hypertension was an independent risk factor for chronic kidney disease $[\mathrm{HR}=2.432,95 \% \text { CI: }(1.575-3.754), \mathrm{p}<0.001]^{25}$; hypertension at nephritis onset and uncontrolled hypertension have been associated with adverse outcomes in patients with SLE. ${ }^{26}$

Our study has some limitations. First, the relatively short time of follow-up precludes us to evaluate the long-term impact on damage accrual; second, not all patients had a renal biopsy. However, in the analyses of the subset with biopsy, the results were quite similar. Adherence was not assessed in the GLADEL cohort and that precluded us to make more confident conclusions about its impact on treatment. Another limitation of our study is the time period when patients were recruited, that was between 1997 and 2004; back then the knowledge about the disease, diagnostic strategies, availability and access to treatments and the use of the WHO classification rather than The 2003 International Society of Nephrology (ISN)/Renal Pathology Society (RPS) classification of lupus nephritis currently being used calls for caution in the interpretation of the results presented. Finally, the distinction between damage and flares was based on the physician's opinion rather than on histopathological information.

An advantage of the present study, however, is the multiethnic nature of the population studied, with the large number of patients included. Additionally, it is important to consider that previous long-term studies have excluded patients who developed ESRD in the first year after LN onset, and the fact that we made a subanalysis including the components of renal damage as an outcome rather than just the creatinine values. ${ }^{10-12}$

In conclusion, data from this large, multiethnic Latin American SLE cohort show that early response to treatment, antimalarial use and high SES were protective of renal damage occurrence. On the other hand, male gender, the presence of hypertension and a higher score in the renal domain of the SLEDAI were risk factors for its occurrence/progression. This emphasises the need to control these risk factors, particularly hypertension and initiate aggressive treatment of nephritis as early as possible. Taken together with the available literature, our data strongly support changing the proteinuria cut-off point at 12 months from $0.5 \mathrm{~g} /$ day to $0.8 \mathrm{~g} /$ day.

\section{Author affiliations}

${ }^{1}$ Rheumatology, Hospital Nacional Guillermo Almenara Irigoyen, EsSalud, Lima, Perú ${ }^{2}$ Unidad de Investigación para la Generación y Síntesis de Evidencias en Salud, Universidad San Ignacio de Loyola, Lima, Perú
${ }^{3}$ Universidad Científica del Sur, Lima, Perú

${ }^{4}$ Escuela de Estadística, Facultad de Ciencias Económicas y Estadística, Universidad Nacional de Rosario, Rosario, Argentina

${ }^{5}$ GLADEL Consultant, Rosario, Argentina

${ }^{6}$ Centro Regional de Enfermedades Autoinmunes y Reumáticas (GO-CREAR), Rosario, Argentina

${ }^{7}$ Hospital Provincial de Rosario, Rosario, Argentina

${ }^{8}$ Hospital Italiano de Buenos Aires, Buenos Aires, Argentina

${ }^{9}$ Hospital Interzonal General de Agudos General San Martín, La Plata, Argentina

${ }^{10}$ Hospital Privado, Centro Médico de Córdoba, Córdoba, Argentina

${ }^{11}$ Hospital Escuela "Eva Perón", Granadeiro Baigorria, Argentina

${ }^{12}$ Universidade Federal da Sao Paulo (UNIFESP), Sao Paulo, Brasil

${ }^{13}$ Hospital das Clinicas HCFMUSP, Faculdade de Medicina, Universidade de Sao

Paulo, Sao Paulo, Brasil

${ }^{14}$ Faculdade de Medicina, Universidade Federal de Goias, Goiânia, Brasil

${ }^{15}$ Servico de Reumatologia, Hospital das Clínicas da Universidade Federal de Pernambuco (HC-UFPE), Recife, Brasil

${ }^{16}$ Grupo de Inmunología Celular e Inmunogenética, Universidad de Antioquia, Medellín, Colombia

${ }^{17}$ Centro de Investigaciones Médico Quirúrgicas (CIMEQ), La Habana, Cuba

${ }^{18}$ Facultad de Medicina, Universidad San Sebastián, Santiago, Chile

${ }^{19}$ Hospital del Salvador, Facultad de Medicina, Universidad de Chile, Santiago, Chile

${ }^{20}$ Centro de Investigación Clínica de Morelia SC, Morelia, Mexico

${ }^{21}$ Hospital Ángeles del Pedregal, Ciudad de México, México

${ }^{22}$ Centro Médico ABC, Ciudad de México, México

${ }^{23}$ Instituto Nacional de Cardiología Ignacio Chávez, Ciudad de México, Mexico

${ }^{24}$ Departamento de Reumatología, Hospital de Especialidades CMN SXXI, Instituto Mexicano de Seguridad Social, Ciudad de México, Mexico

${ }^{25} \mathrm{Hospital}$ General de Occidente de la Secretaría de Salud, Guadalajara, México

${ }^{26}$ Hospital Nacional Edgardo Rebagliati Martins, EsSalud, Lima, Peru

${ }^{27}$ Centro Nacional de Enfermedades Reumáticas, Hospital Universitario de Caracas, Caracas, Venezuela

${ }^{28}$ Hospital Central de San Cristóbal, San Cristóbal, Venezuela

${ }^{29}$ The University of Alabama at Birmingham, Birmingham, Alabama, Alabama, USA

${ }^{30}$ Universidad Peruana Cayetano Heredia, Lima, Perú

Twitter Guillermo Pons-Estel @gponsestel and Manuel F Ugarte-Gil @mugartegil. Acknowledgements We are grateful to Daniel Villalba and Leonardo Grasso for providing expert assistance with the ARTHROS (version 6.0) software. All authors were involved in drafting or revising this article critically for important intellectual content, and all authors approved the final version to be published. Dr Cristina Reategui-Sokolova, Manuel F. Ugarte-Gil, Graciela S. Alarcón' and Bernardo A. Pons-Estel have full access to all the data from the study and take responsibility for their integrity and the accuracy of the analyses performed. We hank our GLADEL patients and staff who made this cohort possible. Preliminary results were presented at the 2019 ACR Congress. https://acrabstracts.org/abstract/predic tors-of-renal-damage-in-systemic-lupus-erythematosus-patients-from-latinamerica/?msg=fail\&shared=email

Collaborators On behalf of GLADEL, María Flavia Ceballos Recalde, Edson Velozo, Jorge A Manni, Sebastián Grimaudo, Judith Sarano, Emilce Schneeberger, María S Arriola, Graciela Gómez, Ana Inés Marcos, Juan Carlos Marcos†, Hugo R Scherbarth†, Jorge A López, Estela L Motta, Cristina Drenkard, Susana Gamron, Laura Onetti, Sandra Buliubasich, Silvana Gentiletti†, Norberto Quagliatto†, Alberto A Gentiletti, Daniel Machado†, Marcelo Abdala, Simón Palatnik†, Guillermo A Berbotto, Carlos A Battagliotti†, Alexandre Wagner S. Souza, Lilian T Lavras Costallat, Manoel Barros Bertolo, Ibsen Bellini Coimbra, Joao C Tavares Brenol, Ricardo Xavier, Tamara Micênic, Ângela Luzia Branco Duarte, Cláudia Diniz Lopes Marques, Tatiana Ferracine Pacheco, José Fernando Molina-Restrepo, Javier Molina-López, Luis A Ramírez, Oscar Uribe, Antonio Iglesias-Rodríguez, Eduardo Egea-Bermejo, Renato A Guzmán-Moreno, José F Restrepo-Suarez, Alfredo Hernández-Martínez, Sergio lacobelli, Leonardo R Guzmán, Abraham García-Kutzbach, Claudia Castellanos, Erwin Cajas, Donato Alarcón-Segovia†, Antonio R Villa, Gerardo Orozco-Barocio, Magali L Estrada-Contreras, María Josefina Sauza del Pozo, Laura E Aranda Baca, Adelfia Urenda Quezada, Guillermo F Huerta-Yañez, José Luis AlfaroLozano, Jorge M Cucho-Venegas, Cecilia P Chung, Magaly Alva-Linares, Isaac Abadi, Neriza Rangel, Jorge Vivas.

†Deceased. 
Contributors DW, GJP-E, RQ, RMS, MPS, LJC, ERS, MAG, AA, FC, GAB, EIS, EFBN, EB, ACdOeSM, NADS, FC, GV, MG-T, GAR-L, LM, OJN, MHC, LAB-F, M-CA, LHS, MP-H, IGdIT, MIS, RC-D and MHE-S contributed to the conception and drafting of the article. CR-S, MFU-G, GBH, BAP-E and GA participated in every phase of the conception and drafting of the article. All listed authors provided critical revision for important intellectual content and final approval.

Funding The GLADEL cohort received no specific funding from agencies in the public, commercial, or not-for-profit sectors for the execution of this work.

Competing interests None declared.

Patient consent for publication Not required.

Provenance and peer review Not commissioned; externally peer-reviewed.

Data availability statement Data are available in a public, open-access repository. All data relevant to the study are included in the article or uploaded as supplemental information.

Open access This is an open access article distributed in accordance with the Creative Commons Attribution Non Commercial (CC BY-NC 4.0) license, which permits others to distribute, remix, adapt, build upon this work non-commercially, and license their derivative works on different terms, provided the original work is properly cited, appropriate credit is given, any changes made indicated, and the use is non-commercial. See: http://creativecommons.org/licenses/by-nc/4.0/.

ORCID iDs

Cristina Reátegui-Sokolova http://orcid.org/0000-0003-3421-2717

Manuel F Ugarte-Gil http://orcid.org/0000-0003-1728-1999

Guillermo J Pons-Estel http://orcid.org/0000-0002-0647-929X

Enrique R Soriano http://orcid.org/0000-0003-3143-1084

\section{REFERENCES}

1 Hanly JG, O'Keeffe AG, Su L, et al. The frequency and outcome of lupus nephritis: results from an international inception cohort study. Rheumatology 2016;55:252-62.

2 Danila MI, Pons-Estel GJ, Zhang J, et al. Renal damage is the most important predictor of mortality within the damage index: data from LUMINA LXIV, a multiethnic US cohort. Rheumatology 2008;48:542-5.

3 Mok CC, Kwok RCL, Yip PSF. Effect of renal disease on the standardized mortality ratio and life expectancy of patients with systemic lupus erythematosus. Arthritis Rheum 2013;65:2154-60.

4 Mok CC. Is treat-to-target in lupus nephritis realistic in clinical practice? Curr Rheumatol Rev 2018;15:2-6.

5 Korbet SM, Lewis EJ, Schwartz MM, et al. Factors predictive of outcome in severe lupus nephritis. Lupus nephritis collaborative study group. Am J Kidney Dis 2000;35:904-14.

6 Chen YE, Korbert SM, Katz RS, et al. Value of a complete or partial remission in severe lupus nephritis. Clin J Am Soc Nephrol 2008;3:46-53.

7 Alarcón GS, McGwin G, Petri M, et al. Time to renal disease and end-stage renal disease in PROFILE: a multiethnic lupus cohort. PLoS Med 2006;3:e396.

8 Reátegui-Sokolova C, Ugarte-Gil MF, Gamboa-Cárdenas RV, et al. Serum uric acid levels contribute to new renal damage in systemic lupus erythematosus patients. Clin Rheumatol 2017:36:845-52.

9 Contreras G, Lenz O, Pardo V, et al. Outcomes in African Americans and Hispanics with lupus nephritis. Kidney Int 1851;2006:1846.
10 Dall'Era M, Cisternas MG, Smilek DE, et al. Predictors of long-term renal outcome in lupus nephritis trials: lessons learned from the Euro-lupus nephritis cohort. Arthritis Rheumatol 2015;67:1305-13.

11 Tamirou F, Lauwerys BR, Dall'Era M, et al. A proteinuria cut-off level of $0.7 \mathrm{~g} /$ day after 12 months of treatment best predicts long-term renal outcome in lupus nephritis: data from the MAINTAIN nephritis trial. Lupus Sci Med 2015;2.

12 Ugolini-Lopes MR, Seguro LPC, Castro MXF, et al. Early proteinuria response: a valid real-life situation predictor of long-term lupus renal outcome in an ethnically diverse group with severe biopsy-proven nephritis? Lupus Sci Med 2017;4:e000213.

13 Pons-Estel BA, Catoggio LJ, Cardiel MH, et al. The GLADEL multinational Latin American prospective inception cohort of 1,214 patients with systemic lupus erythematosus: ethnic and disease heterogeneity among 'hispanics'. Medicine (Baltimore) 2004;83:1-17.

14 Hochberg MC. Updating the American college of rheumatology revised criteria for the classification of systemic lupus erythematosus. Arthritis Rheum 1997:40:1725.

15 Churg J. LHS. Renal disease: classification and atlas of glomerular disease. Tokyo: Igaku-Shoin, 1982.

16 Nived O, Jönsen A, Bengtsson AA, et al. High predictive value of the systemic lupus international collaborating clinics/American college of rheumatology damage index for survival in systemic lupus erythematosus. J Rheumatol 2002;29:1398-400.

17 van Vollenhoven RF, Mosca M, Bertsias G, et al. Treat-to-target in systemic lupus erythematosus: recommendations from an international task force. Ann Rheum Dis 2014;73:958-67.

18 Cheng Y, Li M, Zhao J, et al. Chinese SLE treatment and research group (CSTAR) registry:VIII. Influence of socioeconomic and geographical variables on disease phenotype and activity in Chinese patients with SLE. Int J Rheum Dis 2018;21:716-24.

19 Pons-Estel GJ, Saurit V, Alarcón GS, et al. The impact of rural residency on the expression and outcome of systemic lupus erythematosus: data from a multiethnic Latin American cohort. Lupus 2012;21:1397-404.

20 Kandane-Rathnayake R, Kent JR, Louthrenoo W, et al. Longitudinal associations of active renal disease with irreversible organ damage accrual in systemic lupus erythematosus. Lupus 2019;28:1669-77.

21 Hanaoka H, Kaneko Y, Kuwana M, et al. Early achievement of complete renal response predicts good long-term renal outcome and low systemic damage in newly diagnosed lupus nephritis class III or IV. Mod Rheumatol 2015;25:714-8.

22 Fanouriakis A, Kostopoulou M, Alunno A, et al. 2019 update of the EULAR recommendations for the management of systemic lupus erythematosus. Ann Rheum Dis 2019;78:736-45.

23 Pons-Estel GJ, Alarcón GS, Hachuel L, et al. Anti-malarials exert a protective effect while Mestizo patients are at increased risk of developing SLE renal disease: data from a Latin-American cohort. Rheumatology (Oxford) 2012:51:1293-8.

24 Pons-Estel GJ, Alarcón GS, Burgos PI, et al. Mestizos with systemic lupus erythematosus develop renal disease early while antimalarials retard its appearance: data from a Latin American cohort. Lupus 2013;22:899-907.

25 Sui M, YeX, Ma J, et al. Epidemiology and risk factors for chronic kidney disease in Chinese patients with biopsy-proven lupus nephritis. Intern Med J 2015;45:1167-72.

26 Mahmoud GA, Zayed HS, Ghoniem SA. Renal outcomes among Egyptian lupus nephritis patients: a retrospective analysis of 135 cases from a single centre. Lupus 2015;24:331-8. 